\title{
山西省小麦苗期根系性状及抗旱特性分析
}

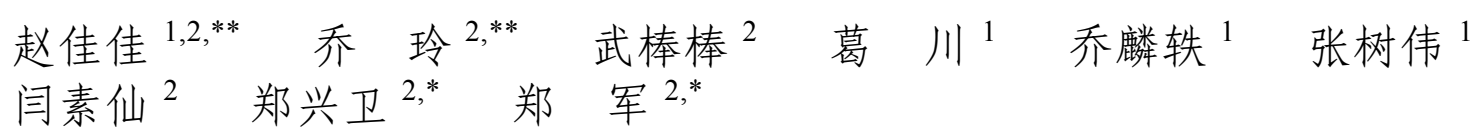
${ }^{1}$ 山西农业大学有机旱作农业研究院 / 有机旱作山西省重点实验室, 山西太原 $030006 ;{ }^{2}$ 山西农业大学小麦研究所, 山西临汾
041000

摘 要: 小麦苗期根系形态是成株期根系分布的基础, 与抗逆和产量密切相关, 全面认识苗期根系及抗旱特性, 对 于抗旱优异种质的利用和早期筛选具有重要意义。采用 239 份山西省小麦品种(系)在土培条件下, 研究了苗期根系性 状及对水分胁迫的响应。结果表明, 正常生长下山西小麦苗期根系性状多样性丰富, 地方种变异最大; 不同年代品种 中, 除最大根长随年代略下降外, 其他性状均呈先升后降的趋势; 不同根系性状对水分胁迫响应存在差异, 总根长 对水分最敏感, 其次为根表面积、根体积和根生物量, 最大根长和平均根数不敏感。苗期根系综合抗旱能力随年代呈 先降后升的趋势, 地方种和 20 世纪 70 年代品种多为中抗, 80 和 90 年代的品种抗旱性较低, 2000 年以后审定品种的 抗性较高, 其中旱地品种抗性最好。苗期根系抗旱特性与产量性状相关分析发现, 最大根长、总根长、根体积和根生 物量与雨养条件下的千粒重和产量显著正相关, 最大根长和根生物量与成株期抗旱性也显著正相关。因此苗期最大 根长和根生物量可作为半干旱地区旱地育种过程中抗旱性和产量的早期穊选指标。

关键词: 山西小麦; 苗期根系; 抗旱特性; 演变趋势

\section{Seedling root characteristics and drought resistance of wheat in Shanxi province}

ZHAO Jia-Jia ${ }^{1,2, * *}$, QIAO Ling ${ }^{2, * *}$, WU Bang-Bang ${ }^{2}$, GE Chuan ${ }^{1}$, QIAO Lin-Yi ${ }^{1}$, ZHANG Shu-Wei ${ }^{1}$, YAN Su-Xian ${ }^{2}$, ZHENG Xing-Wei, ${ }^{2, *}$, and ZHENG Jun, ${ }^{2, *}$

${ }^{1}$ Academy of Organic Dry Farming Agricultural Research, Shanxi Agriculture University, the Key Laboratory of Organic Dry Farming of Shanxi Province, Taiyuan 030006, Shanxi, China; ${ }^{2}$ Institute of Wheat Research, Shanxi Agriculture University, Linfen 041000, Shanxi, China

\begin{abstract}
Wheat root morphology at the seedling stage is the basis of root distribution at the adult stage. It is closely related to stress resistance and yield. A comprehensive understanding of the root system characteristics at seedling stage and drought resistance is of great significance for the excellent germplasm utilization and early screening of drought resistance. Using 239 wheat varieties (lines) from Shanxi province, the root traits at seedling stage and their response to water stress were evaluated. The results showed that under normal growth, Shanxi wheat had a great variation in root traits at seedling stage, with the greatest variation in landraces. The maximum root length (MRL) tended to decrease slightly with the years, while other root traits were first increased and then decreased. There were differences among the root traits in response to water stress. The total root length (TRL) is the most sensitive to water, followed by root surface area (RSA), root volume (RV) and root biomass. The maximum root length $(\mathrm{MRL})$ and the average number of roots $(\mathrm{RN})$ were insensitive. The drought resistance of seedling roots showed a trend of decreasing first and then increasing with the years. Landraces and varieties released from 1970 to 1979 had moderately resistance to water stress, varieties released from 1980 to 1999 had lower drought resistance, and varieties released after 2000 had the better
\end{abstract}

\footnotetext{
本研究由有机旱作山西省重点实验室开放基金项目(201805D111015-2), 山西省自然科学基金项目(201901D211567), 山西省农业科学 院科技创新项目(YCX2018413)和山西省重点研发计划项目(201803D421021)资助。

This study was supported by the Key Laboratory of Organic Dry Farming of Shanxi Province (201805D111015-2), the Natural Science Foundation of Shanxi Province (201901D211567), the Agricultural Science and Technology Project (YCX2018413), and the Shanxi Province Key Research and Development Program (201803D421021).

*通信作者(Corresponding authors)：郑军, E-mail: sxnkyzj@126.com; 郑兴卫, E-mail: smilezxw@126.com

** 同等贡献(Contributed equally to this work)

第一作者联系方式: 赵佳佳, E-mail: jjzh1990@163.com
}

Received (收稿日期): 2020-06-08; Accepted (接受日期): 2020-09-13; Published online (网络出版日期): 2020-09-25.

URL: https://kns.cnki.net/kcms/detail/11.1809.S.20200925.1646.004.html 
resistance, of which the dryland varieties were the best resistance. Correlation analysis of the seedling root characteristics and yield related traits suggested that the maximum root length, total root length, root volume and root biomass were significantly positively correlated with 1000-kernel weight and yield under rain-fed conditions, and the maximum root length and root biomass were also significantly positively correlated with adult plant drought resistance. The present study suggests that the maximum root length and root biomass at the seedling stage can be used as early generation selection parameters for drought resistance and yield in dryland breeding in semi-arid areas.

Keywords: Shanxi wheat; seedling root system; drought resistance characteristics; evolution trend.

根系具有固着植物, 吸收、咜藏、运输水分和 营养物质的功能。对于小麦而言，根系形态和性能 直接影响地上部分的生长、发育和产量表现，是小 麦具有节水、抗倒、耐热、落黄等良好特性的根本 所在 ${ }^{[1-3]}$ 。成株期根系发育易受到土壤和栽培措施影 响, 常规取样破坏性大、工程复杂, 使得表型调查难 以高效实施。目前, 小麦根系形态的研究方法主要 有挖掘法、塑管土柱法、网袋法、根室观察法、三 维坐标容器法、同位素示踪法和微根管系统等 ${ }^{[3-4]}$ 。 这些方法虽能直接或间接反映成株期根系生长状态, 但极少用于大规模群体取样, 导致小麦遗传改良研 究主要关注在地上部分的重要农艺性状方面, 对“隐 藏的另一半”一根系的研究相对欠缺。因此, 寻找 准确、便捷的根系形态检测方法一直倍受重视。

小麦初生根是指种子萌发出 1 条胚根和另外 4 6 条种子根, 对根系建成和后期生长发育具有重 要作用 ${ }^{[5-7]}$ 。早期研究已证实发育良好的初生根有助 于促进次生根的建成 ${ }^{[8]}$, 苗期根系形态可有效指示 成株期的根群分布及特点 ${ }^{[9-11]}$ 。此外, 初生根数量和 活力对小麦产量也具有重要贡献, Xie 等 ${ }^{[12]}$ 发现苗期 总根长和初生根数目与穗粒数、千粒重和地上生物 量正相关; 初生根发育的深层根系可利用深土层储 水, 直接关系到成株期抗旱性和产量 ${ }^{[13-14]}$ 。An 等 ${ }^{[15]}$ 和 Fan 等 ${ }^{[16]}$ 发现控制苗期根系的 QTL 同时调控营养 吸收和抗逆; 且有些调控苗期根系生长的基因在干 旱胁迫下高表达 ${ }^{[5]}$ 。可见苗期根系发育与小麦的抗 逆和产量密切相关。目前苗期根系性状调查常采用 营养液法、凝胶室法、纸培法、砂培法和土培法 等 ${ }^{[17-21]}$ 。这些方法误差小、操作简便、通量高、损 伤小, 取样后结合图像分析, 可完成对苗期根系形 态的快速检测。肖永贵等 ${ }^{[22]}$ 研究了骨干亲本·京 411 , 及 14 个衍生品种的苗期根系, 发现衍生品种的最大 根长和根系生物量较京 411 显著改良; 景药莲等 ${ }^{[23]}$ 对 35 个不同栽培类型的小麦品种(系)苗期根系与抗 旱性关系研究, 发现中间型根系的品种反复干旱处 理后存活率高, 抗旱性强; 马富举等 ${ }^{[24]}$ 利用 2 个耐 旱性不同的品种, 发现干旱胁迫下苗期根系通过较
高的生物量和根长增加对水分的吸收; Dhanda 等 ${ }^{[25]}$ 利用 30 个品种探讨了早期抗旱评价指标, 认为根长 和根冠比可作为预测耐旱的性状指标。用遗传群体 研究苗期根系也有报道, Landjeva 等 ${ }^{[26]}$ 利用重组自 交系群体检测根系性状与抗旱性的关系, 认为根长 可作为苗期抗旱的指标; 周晓果等 ${ }^{[27]}$ 利用双单倍体 群体发现苗期根数和根干重与抗旱性显著相关。可 见, 小麦苗期根系与抗旱性高度相关已受到普遍认 可。我国西南、西北、黄土高原和长江中下游等麦 区的小麦根系研究也有报道 ${ }^{[28-31]}$, 但大多通过遗传 群体和个别品种进行, 并未建立起可用于抗旱育种 的苗期篲选指标。因此, 系统研究干旱胁迫下苗期 根系的形态特征和生理功能亟待进行。

山西省小麦种植历史悠久, 目前出土距今已有 3000 多年的小麦籽粒, 相同年代的面饼也有发现 ${ }^{[32]}$ 。 山西地理位置独特, 位于黄土高原东部, 属温带季 风性气候, 北邻内蒙古草原, 南接中原腹地, 东依 太行, 西界黄河, 外缘有山脉环绕, 不受海风气候 的影响; 由于内蒙古冬季冷气团形成的大陆性季风 性气候, 自南向北温差较大。全省年降水量在 400 $650 \mathrm{~mm}$, 小麦种植区域为典型的半干旱地区, 使得 山西小麦历来以抗旱闻名全国，如晋麦 33、长 6878 和晋麦 47 等品种被选为国家旱地小麦区试对照品 种, 其中晋麦 47 从 20 世纪 90 年代至今一直作为黄 淮北片旱地、山西南部旱地和陕西渭北旱地区试对 照 ${ }^{[33]}$ 。以山西省地方种和不同年代育成品种为材料 探究半干旱地区的小麦苗期根系及抗旱特性具有较 强的代表性。本文系统研究了山西省小麦品种(系) 苗期根系性状及其对干旱胁迫响应，鉴选出抗旱性 评价的根系指标, 研究结果有助于半干旱地区小麦 抗旱遗传改良。

\section{1 材料与方法}

\section{1 试验材料}

山西省小麦品种(系)共 239 份, 包括建国以来山 西省育成品种 198 份, 占审定品种总数的 $90 \%$, 其 中旱地品种 96 个, 水地品种 102 个; 地方农家种 41 
份, 为中国小麦核心种质中来源于山西省的地方种, 材料信息见附表 1 。育成品种来源于各育种单位和 本课题保存, 地方种为中国农业科学院作物科学研 究所郝晨阳副研究员提供。

所有材料于 2017-2018 年度和 2018-2019 年 度种植于小麦研究所试验基地（山西省临汾市 $\left.36^{\circ} 2^{\prime} \mathrm{N}, 111^{\circ} 18^{\prime} \mathrm{E}\right), 10$ 月中旬播种, 翌年 6 月中旬收 获。每个材料播种 2 行, 行长 $1.5 \mathrm{~m}$, 每行 30 粒。设 旱地和水地 2 种生长条件, 旱地为雨养条件(生育期 平均降雨量约为 $194 \mathrm{~mm}$, 图 1); 水地于越冬期、拔 节期和灌浆期地下水灌溉, 灌溉量均为 $700 \mathrm{~m}^{3} \mathrm{hm}^{-2}$ $(70 \mathrm{~mm})$ 。成熟后各品种随机选取 5 株, 测量株高、 小穗数、穗粒数和千粒重等性状。2 个生育期内自 然降水和常年相近, 未发生极端天气和严重自然灾 害, 小麦生长情况良好。

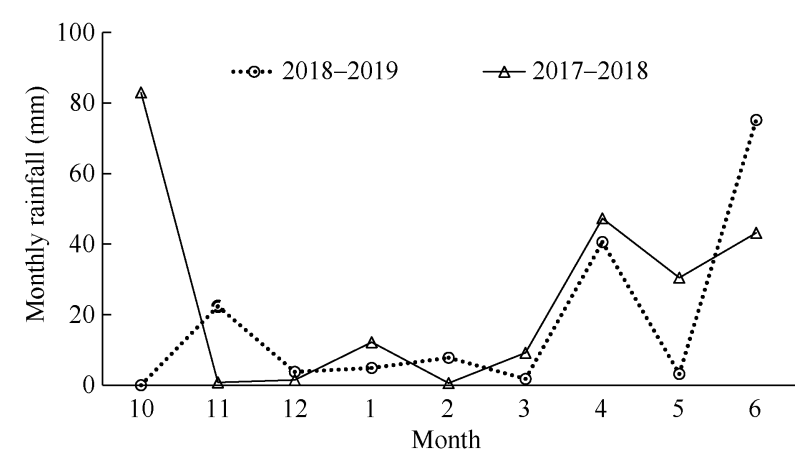

图 1 小麦生育期的月降雨量

Fig. 1 Monthly rainfall of two years during whole growth stage in wheat

\section{2 苗期培养及干旱胁迫处理}

挑选籽粒饱满均一、无病虫害的种子, 腹沟朝 下均匀的摆放在培养血中，用蒸馏水浸泡吸胀萌发; 种子露白后, 选取 6 粒萌发程度一致的种子, 点播在 含有蛭石和 $100 \mathrm{~mL}$ 水的培养杯中 (直径为 $7 \mathrm{~cm}$, 高 $8 \mathrm{~cm}$ ), 于光强为 $500 \mu \mathrm{mol} \mathrm{m} \mathrm{m}^{-2} \mathrm{~s}^{-1}$, 湿度为 $70 \%$, 光 温周期为 $20^{\circ} \mathrm{C} 16 \mathrm{~h} / 16^{\circ} \mathrm{C} 8 \mathrm{~h}$ 的人工气候室培养。设 正常水分和 19.2\% PEG-6000 (polyethylene glycol, PEG)模拟干旱胁迫 2 种方式, 各设 3 次重复, 共 6 个 处理。每天相同时间点播 1 个处理的材料(239份), 各 处理出苗7 $\mathrm{d}$ 后进行正常补水/胁迫处理; 继续生长 $4 \mathrm{~d}$ 后从土壤中收集根系完整的植株, 清洗后, 分别 测定根系形态。

\section{3 根部性状测定}

根状扫描仪(Microtek Scanmakeri 800 plus)扫描 幼苗根部图片, 根数(average number of roots, RN)、 总根长(total root length, TRL)、根表面积(root surface area， RSA) 和根体积 (root volume, RV) 采用 Win-RHIZO 系统(Regent Instruments Inc., Quebec, Canada)测量获得, ImageJ 软件测量最大根长(MRL), 每个品种测定 5 株。幼苗自根茎相接处分开, 称量 地上部和地下部鲜重(shoot fresh weight, SFW 和 root fresh weight, RFW), 再分别放在烘箱 $105^{\circ} \mathrm{C}$ 杀青 20 $\min , 70^{\circ} \mathrm{C}$ 烘干至恒重后, 称量地上部和地下部干重 (shoot dry weight, SDW 和 root dry weight, RDW), 计 算根冠比(root/shoot ratio, RSR)和地上、地下含水量 (water content of shoot, SWC 和 water content of root, RWC)，每个品种测定 5 株取平均值。

露点渗透压仪(Wescor 5600, 美国)测定叶片及 根部的渗透摩尔浓度, 按照公式 $\mathrm{w}=-\mathrm{ic} \times \mathrm{R} \times \mathrm{T}$ 计算 渗透势, $\mathrm{R}$ 是气体常数, 通常取值为 $0.008314 ; \mathrm{T}$ 为凯 氏温度, $\mathrm{T}=273+\mathrm{t}, \mathrm{t}$ 为室温(摄氏度); ic 是被测样品 的渗透摩尔浓度 $\left(\mathrm{mmol} \mathrm{kg}^{-1}\right)$ 。

\section{4 抗旱性评价方法}

参照文献 ${ }^{[34]}$ 计算抗旱系数 (drought-tolerance coefficient, DTC)、隶属函数、综合抗旱评价值 $(D)$ 等指标, 抗旱系数为处理与对照的相对值, 公式为:

$\mathrm{DTC}_{i}=X_{i}(k) / \mathrm{CX}_{i}(k)$

式中, $X_{i}(k)$ 和 $\mathrm{CX}_{i}(k)$ 分别表示处理和对照性状测 定值。

对所有性状 DTC 进行主成分分析，再计算其隶 属函数值 $U\left(X_{j}\right)$, 公式为:

$$
U\left(X_{j}\right)=\left[\mathrm{CI}_{j}-\mathrm{CI}_{\min }\right] /\left[\mathrm{CI}_{\max }-\mathrm{CI}_{\min }\right]
$$

式中, $U\left(X_{j}\right)$ 表示第 $j$ 个主成分的隶属函数值, $\mathrm{CI}_{\min }$ 表 示所有材料该主成分最小值, $\mathrm{CI}_{\max }$ 表示所有材料该 主成分的最大值。

各综合指标权重 $W_{j}$ :

$W_{j}=P_{j} / \sum(j=1)^{n} P_{j} \quad(j=1,2, \ldots, n)$ 式中, $W_{j}$ 表示第 $j$ 个主成分在所有主成分中的重要程度, $P_{j}$ 表示各材料第 $j$ 个综合指标贡献率, $n$ 为主成分数量。

$D_{j}$ 为综合抗旱能力评价值, $D_{j}$ 越高, 表示该材 料的综合抗旱能力越大。

$D_{j}=\sum(j=1)^{n} U\left(X_{j}\right) W_{j} \quad(j=1,2, \ldots, n)$

为了综合考虑苗期根系特性, 对根系性状进行 归一化处理, 与性状相对抗旱系数结合评价苗期的 抗旱性。

$$
\begin{aligned}
& X_{i}^{\prime}(k)=\left[X_{i}(k)-X_{\min }\right] /\left[X_{\max }-X_{\min }\right] \\
& \mathrm{DTC}_{i}{ }^{\prime}=X_{i}^{\prime}(k) \mathrm{DTC}_{i}
\end{aligned}
$$

$X_{i}^{\prime}(k)$ 为数据归一化处理结果, $\mathrm{DTC}_{i}{ }^{\prime}$ 为苗期根系 抗旱特征值。 


\section{5 数据分析}

用 Microsoft Excel 2010 软件对数据进行常规统计 分析, SPSS 24.0 软件进行方差、相关性和主成分分析。

\section{2 结果与分析}

\section{1 小麦苗期根系性状变异}

正常水分条件下, 山西小麦苗期根部性状总体 变异幅度较大, 除地上和地下含水量 (SWC 和 RWC) 的变异系数较小外, 其他性状均在 $11 \%$ 以上, 其中 总根长(TRL)、根系表面积(RSA)、根体积 $(R V)$ 和根 干、鲜重 $(\mathrm{RFW}, \mathrm{RDW})$ 等性状变异系数在 $17 \%$ 以上, 说明山西小麦苗期根系表型丰富, 品种间根系性状 差异明显(图 2-A 和表 1)。品种类型中以育成品种的 根系性状值较大, 除旱地品种地上干、鲜量 (SFW, $\mathrm{SDW})$ 变异系数较大外, 其他性状均以地方种变异 丰富; 育成品种中旱地品种根系变异丰富, 但水地 品种根系性状值较大。

\section{2 干旱胁迫下根系性状变异}

PEG 处理抑制了苗期根系生长, 有些品种敏感, 胁迫前后根系差异大, 如长麦 6973; 有些品种胁迫 前后根系差异小，如运旱 21-30 (图 2-B)。胁迫条件 下苗期根系形态性状整体受到抑制，其中 TRL 的降 幅最大，为 $33.94 \% \sim 39.37 \%$, 其余依次为 RSA、RV、
最大根长(TRL)、RFW 和 RN (表 2); 各性状变异系 数变小, 表明缺水条件下根系形态性状变异性低。 采用抗旱系数(DTC)分析不同性状的相对抗性表明, 山西小麦苗期根系性状的 DTC 变异丰富(图 3), 不 同性状对胁迫的响应存在差异, 总根长的抗旱系数 大值为 1.5 ; 除根冠比外, 其他性状的抗旱系数也较 低，多分布在 1.0 以下。胁迫下根系生物量(RFW 和
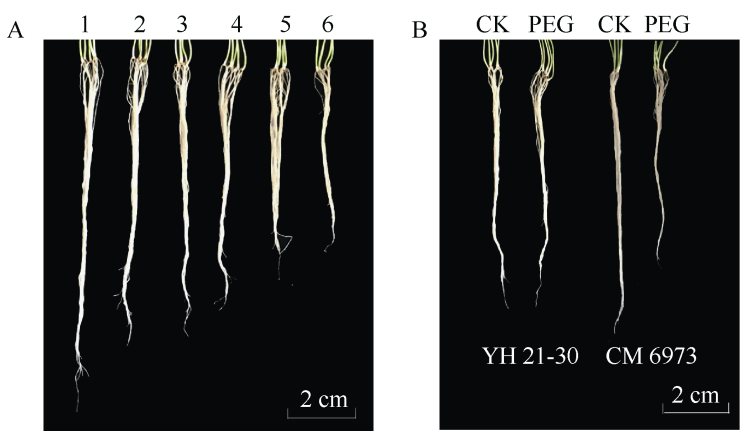

图 2 山西小麦苗期根部性状表型

Fig. 2 Root traits of wheat at seedling stage in Shanxi province A：正常条件下小麦苗期根系多样性。1：晋春 16; 2: 玉兰麦; 3: 晋麦 79; 4: 临优 145; 5: 晋麦 73; 6: 晋麦 86。B: 正常 (CK)和胁 迫(PEG)处理下苗期根系表型, YH 21-30: 运旱 21-30; CM 6973: 长麦 6973。

A: diversity of seedling root with five plants under control in wheat; 1: Jinchun 16; 2: Yulanmai; 3: Jinmai 79; 4: Linyou 145; 5: Jinmai 73; 6: Jinmai 86. B: difference of root traits at seedling stage between control and drought stress. YH 21-30: Yunhan 21-30; CM 6973: Changmai 6973.

表 1 正常水分条件下山西苗期小麦根部性状分析

Table 1 Analysis of root traits at seedling stage in Shanxi province under normal condition in wheat

\begin{tabular}{|c|c|c|c|c|c|c|c|c|c|}
\hline \multirow{2}{*}{$\begin{array}{l}\text { 性状 } \\
\text { Trait }\end{array}$} & \multicolumn{3}{|c|}{ 地方种 Landrace } & \multicolumn{3}{|c|}{ 旱地品种 Dryland cultivar } & \multicolumn{3}{|c|}{ 水地品种 Irrigated cultivar } \\
\hline & $\begin{array}{c}\text { 变幅 } \\
\text { Range }\end{array}$ & $\begin{array}{l}\text { 均值 } \\
\text { Mean }\end{array}$ & $\begin{array}{c}\text { 变异系数 } \\
\text { CV (\%) }\end{array}$ & $\begin{array}{c}\text { 变幅 } \\
\text { Range }\end{array}$ & $\begin{array}{l}\text { 均值 } \\
\text { Mean }\end{array}$ & $\begin{array}{c}\text { 变异系数 } \\
\text { CV (\%) }\end{array}$ & $\begin{array}{c}\text { 变幅 } \\
\text { Range }\end{array}$ & $\begin{array}{l}\text { 均值 } \\
\text { Mean }\end{array}$ & $\begin{array}{c}\text { 变异系数 } \\
\text { CV }(\%)\end{array}$ \\
\hline 最大根长 MRL $(\mathrm{cm})$ & $13.42-25.10$ & $17.99 \pm 0.40$ & 14.10 & $11.50-22.33$ & $16.95 \pm 0.24$ & 13.77 & $11.75-22.77$ & $17.27 \pm 0.24$ & 14.21 \\
\hline 总长度 TRL $(\mathrm{cm})$ & $48.85-194.20$ & $114.75 \pm 6.31$ & 35.24 & $45.45-219.74$ & $123.66 \pm 3.56$ & 28.03 & $58.79-250.98$ & $135.79 \pm 3.81$ & 28.45 \\
\hline 表面积 RSA $\left(\mathrm{cm}^{2}\right)$ & $5.82-20.97$ & $11.67 \pm 0.51$ & 27.79 & $6.59-23.35$ & $13.79 \pm 0.34$ & 23.95 & $7.76-21.46$ & $14.73 \pm 0.29$ & 19.92 \\
\hline 体积 RV $\left(\mathrm{cm}^{3}\right)$ & $0.06-0.27$ & $0.125 \pm 0.006$ & 29.14 & $0.08-0.31$ & $0.16 \pm 0.005$ & 27.07 & $0.09-0.29$ & $0.17 \pm 0.004$ & 21.01 \\
\hline 平均根数 $\mathrm{RN}$ & $3.00-5.67$ & $4.71 \pm 0.09$ & 12.89 & $3.00-7.33$ & $5.35 \pm 0.07$ & 13.01 & $3.33-7.00$ & $5.26 \pm 0.06$ & 11.38 \\
\hline 地上鲜重 SFW (g) & $0.07-0.16$ & $0.11 \pm 0.003$ & 17.86 & $0.09-0.19$ & $0.136 \pm 0.002$ & 16.68 & $0.09-0.20$ & $0.135 \pm 0.002$ & 14.93 \\
\hline 地上干重 SDW (g) & $0.01-0.02$ & $0.013 \pm 0.0004$ & 20.31 & $0.01-0.03$ & $0.018 \pm 0.0003$ & 17.92 & $0.01-0.02$ & $0.018 \pm 0.0003$ & 14.75 \\
\hline 根鲜重 RFW (g) & $0.06-0.14$ & $0.099 \pm 0.003$ & 19.94 & $0.08-0.20$ & $0.124 \pm 0.003$ & 21.30 & $0.08-0.19$ & $0.132 \pm 0.0025$ & 19.04 \\
\hline 根干重 RDW (g) & $0.005-0.012$ & $0.008 \pm 0.0002$ & 18.89 & $0.01-0.02$ & $0.011 \pm 0.0003$ & 22.11 & $0.01-0.02$ & $0.011 \pm 0.0002$ & 17.28 \\
\hline 鲜根冠比 FRSR & $0.56-1.24$ & $0.90 \pm 0.023$ & 16.36 & $0.48-1.37$ & $0.92 \pm 0.018$ & 19.24 & $0.54-1.45$ & $0.99 \pm 0.017$ & 17.41 \\
\hline 干根冠比 DRSR & $0.39-0.92$ & $0.64 \pm 0.017$ & 16.66 & $0.37-0.92$ & $0.62 \pm 0.012$ & 18.82 & $0.37-1.01$ & $0.65 \pm 0.011$ & 17.76 \\
\hline 地上含水量 SWC & $0.86-0.90$ & $0.88 \pm 0.001$ & 0.98 & $0.84-0.90$ & $0.87 \pm 0.001$ & 1.29 & $0.84-0.89$ & $0.87 \pm 0.001$ & 1.17 \\
\hline 地下含水量 RWC & $0.9-0.93$ & $0.92 \pm 0.001$ & 0.89 & $0.89-0.94$ & $0.91 \pm 0.001$ & 1.14 & $0.89-0.93$ & $0.91 \pm 0.001$ & 0.93 \\
\hline
\end{tabular}

MRL: maximum root length; TRL: total root length; RSA: root surface-area; RV: root volume; RN: root number; SFW: shoot fresh weight; SDW: shoot dry weight; RFW: root fresh weight; RDW: root dry weight; FRSR: fresh root/shoot ratio; DRSR: dry root/shoot ratio; SWC: water content of shoot; RWC: water content of root; CV: coefficient of variation. 


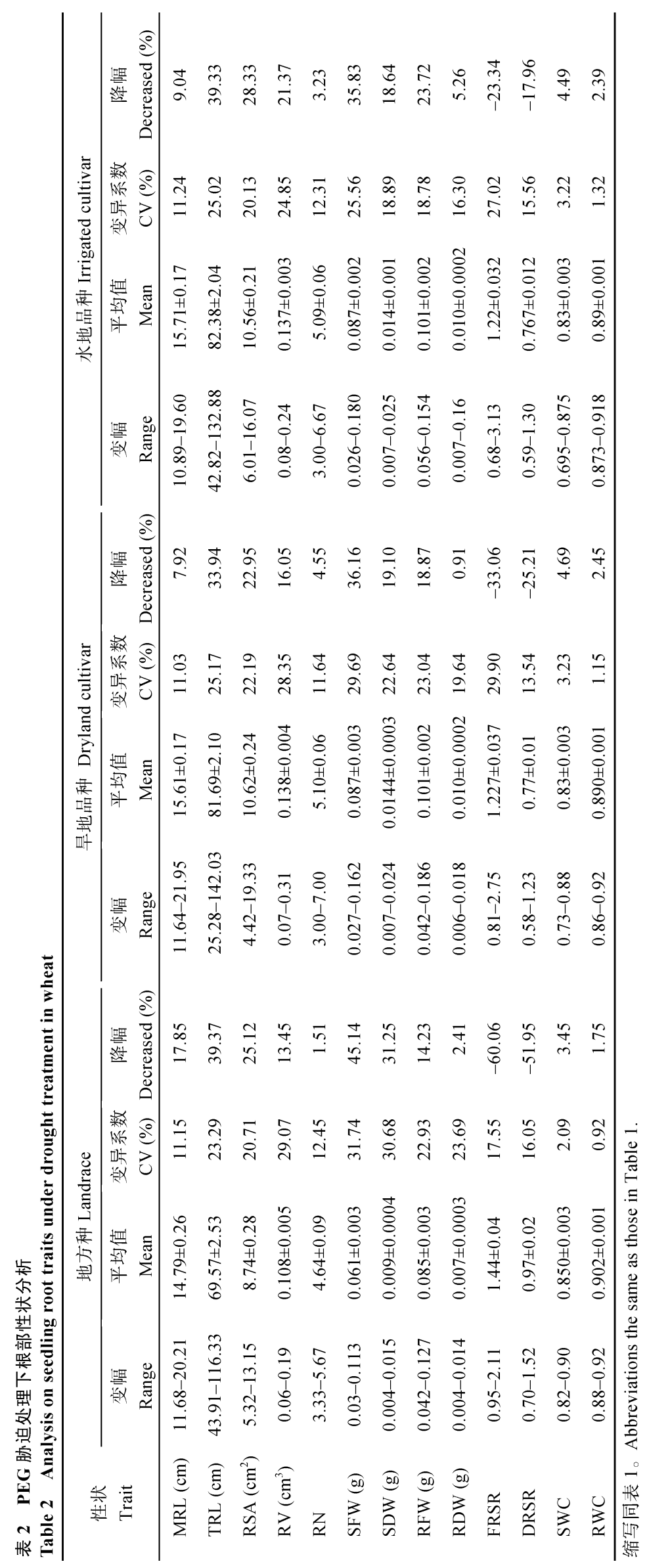


$\mathrm{RDW})$ 和地上生物量(SFW 和 SDW)均降低, 但 SFW 和 SDW 降幅大, 根冠比(FRSR 和 DRSR)增大, 抗旱 系数分布在 1.0 1.5 之间, 表明干旱胁迫对地上部的 抑制作用大于根系。整体而言, TRL、RSR、SFW 和 SDW 对水分胁迫最敏感，其次为 RSA、RV、RFW 和 RDW, MRL 和 RN 对水分敏感性低(表 2 和图 3)。

地方种地上部受抑制程度大于育成品种, 地上 鲜、干重的抗旱系数 $\left(\mathrm{DTC}_{\mathrm{SFW}}\right.$ 和 $\left.\mathrm{DTC}_{\mathrm{SDW}}\right)$ 小, 根系生 物量和根冠比的抗旱系数 $\left(\mathrm{DTC} \mathrm{C}_{\mathrm{RFW}} 、 \mathrm{DTC}_{\mathrm{RDW}}\right.$ 和 $\mathrm{DTC}_{\mathrm{FRSR}} 、 \mathrm{DTC}_{\mathrm{DRSR}}$ )则表现为地方种大于育成品种; 胁迫下旱地品种的 TRL、MRL、RSA 和 RDW 降幅 较小, 抗旱系数除 $\mathrm{DTC}_{\mathrm{RN}}$ 外, 其他性状的 DTC 以旱 地品种最大, 地方种和水地品种较小。整体而言, 旱 地品种根系对干旱胁迫的敏感性低(表 2 和图 3)。

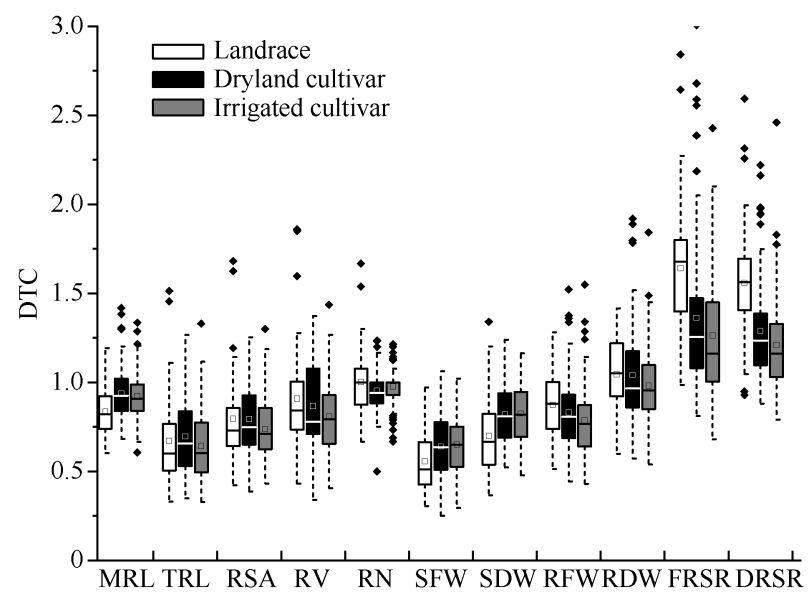

图 3 山西小麦苗期根系性状的抗旱系数

Fig. 3 DTC (drought-tolerance coefficient) of root traits at seedling stage of wheat in Shanxi province

\section{3 小麦苗期根系性状演变趋势}

对农艺性状演变趋势分析, 可以归纳出品种适 应自然和人工选择的规律。山西小麦苗期根系性状 随年代变化有 3 种趋势, 其中 MRL 随年代略降, 以 地方种最高; TRL、RSA、RV、RN 及 RFW、RDW 呈先增后降趋势, 以 20 世纪 80 和 90 年代品种最大; FRSR 和 DRSR 随年代变化不明显(图 4)。各性状抗 旱系数随年代变化趋势与根系性状演变不同, $\mathrm{DTC}_{\mathrm{MRL}}$ 和 $\mathrm{DTC}_{\mathrm{RDW}}$ 随年代缓慢增大; $\mathrm{DTC}_{\mathrm{TRL}}$ 、 $\mathrm{DTC}_{\mathrm{RSA}} 、 \mathrm{DTC}_{\mathrm{RV}} 、 \mathrm{DTC} \mathrm{RFW}_{\mathrm{RFW}} 、 \mathrm{DTC}_{\mathrm{RFW}}$ 和 $\mathrm{DTC}_{\mathrm{RDW}}$ 先 降后增。整体上随着人工选择与品种改良, 地方种 到育成品种根系性状先增后降，80、90 年代根系性 状最大, 90 年代之后随着育种水平的提高, 抗旱能 力不断提高。

\section{4 苗期抗旱性综合评价}

抗旱性受多因素控制，利用单一指标鉴定品种 抗旱性存在局限性, 将较多指标转换为综合抗旱 $D$ 值评价抗旱性已得到认可。山西小麦苗期 $D$ 值变化 范围为 $0.273 \sim 0.803$, 可分为高抗 $(D \geq 0.611)$ 、中 抗(0.566 $\leq D<0.611) 、 一$ 般(0.477 $\leq D<0.566)$ 、 较敏感 $(0.432 \leq D<0.477)$ 和敏感 $(D<0.432) 5$ 级。 各级材料份数依次为 $38 、 36 、 80 、 46$ 和 39 份, 分 别占总数的 $15.89 \% 、 15.06 \% 、 33.47 \% 、 19.25 \%$ 和 $16.32 \%$ 。高抗品种包括: 长麦 6135 、晋麦 88 、长 6878 和运旱 21-30 等旱地品种 20 份, 长 6452、临优 2018、 晋太 114 和晋麦 74 等水地品种 11 份, 以及白秃麦、 齐穗麦和绛州红等地方种 7 份。

各年代均以旱地品种的 $D$ 值较高, 抗旱性最好, 20 世纪 80 和 90 年代的品种抗旱能力变弱, 大多为 一般和较敏感类型, 地方种和 20 世纪 70 年代的品 种抗性一般, 2000 年以后审定品种的抗旱性整体表 现较好, $D$ 值主要分布在中抗和高抗之间(图 5), 表 明随着育种水平的不断提高, 根系抵抗旱胁迫的能 力增强, 能更好的适应缺水环境。

\section{5 渗透势监测}

干旱环境下，保持良好的水分状态是植物抗旱 的主要方式，监测胁迫前后渗透势变化可有效反映 出植株在干旱条件下的渗透调节能力 ${ }^{[35-36]}$ 。依据苗 期 $D$ 值分级, 随机选取抗旱型和敏感型的小麦品种 各 5 份, 测定正常和胁迫下叶片和根系渗透势, 其 中晋麦 88 、晋麦 82 、晋麦 83 、运旱 21-30 和晋麦 90 等品种抗性好，晋春 16、晋春 14、运旱 20410 、 长麦 5973 和玉兰麦等抗性较差。与正常生长相比, 干旱胁迫下各品种的叶片和根系渗透势均降低, 根 系的降幅较叶片小; 抗旱性好的品种根系和叶片的 渗透势下降程度大于抗旱性弱的品种, 渗透调节能 力较强(图 6)。此外, 胁迫处理下根系与叶片的渗透 势差增大, 地上部分对干旱胁迫较根系更敏感。

\section{6 苗期根系与产量性状的关系}

评价粮食作物抗旱性要兼顾丰产性，通过水旱 地产量性状计算抗旱系数求得成株期 $D$ 值。苗期根 系性状抗旱特性与成株期产量相关性分析表明，苗

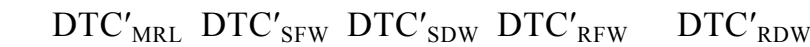
与成株期 $D$ 值显著正相关，其中 $\mathrm{DTC}^{\prime} \mathrm{SDw}^{\prime}$ 和 $\mathrm{DTC}_{\mathrm{RDW}}^{\prime}$ 与成株期 $D$ 值极显著相关, $\mathrm{DTC}^{\prime}{ }_{\mathrm{RN}}$ 与成株 期 $D$ 值显著负相关(表 3)。DTC ${ }_{\mathrm{MRL}}$ 与雨养条件下千 
A
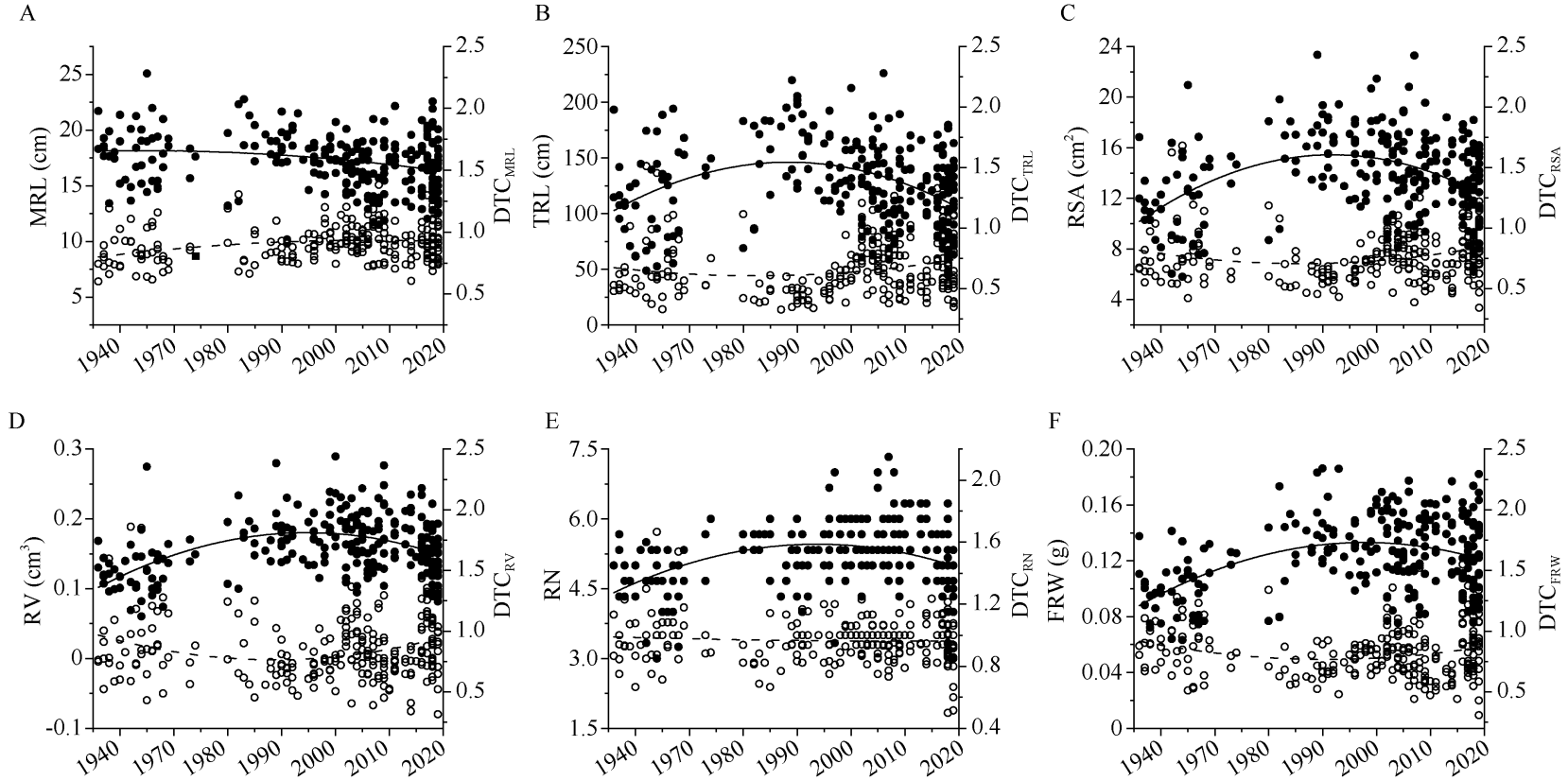

G
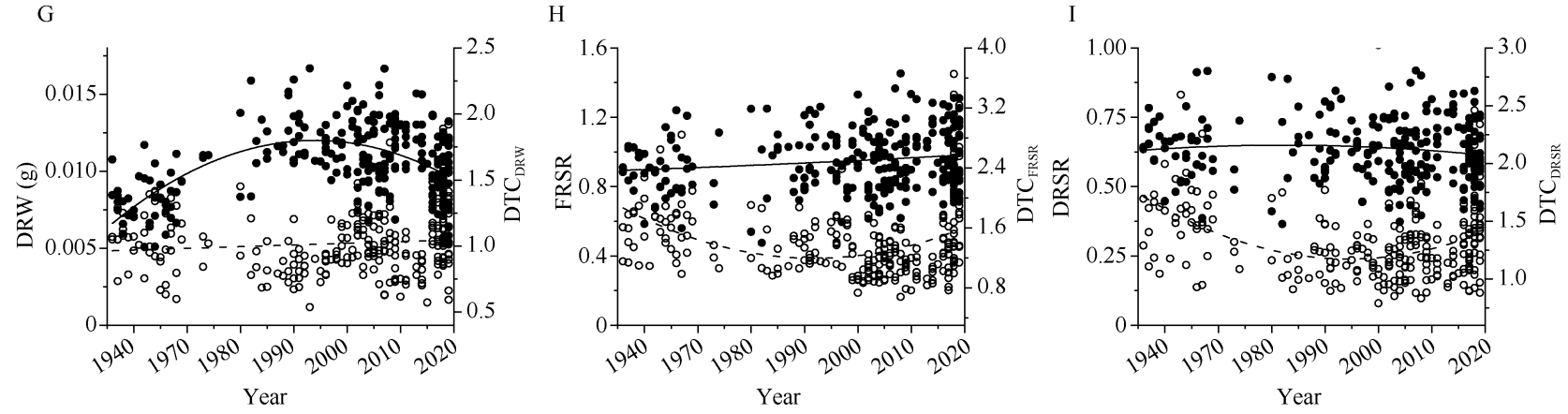

图 4 山西小麦苗期根部性状特征演化

Fig. 4 Evolution of seedling root traits of wheat in Shanxi province 缩略同表 1。Abbreviations are the same as those given in Table 1.

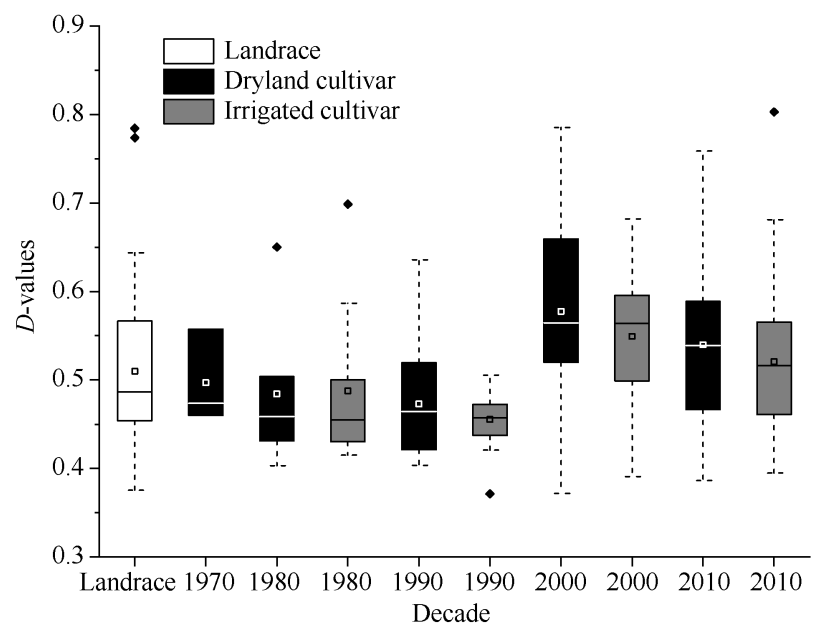

图 5 山西小麦苗期根系抗旱性鉴定

Fig. 5 Drought-tolerance evaluation of wheat root at seedling stage in Shanxi province

粒重和产量显著正相关, 与灌溉下穗粒数显著负相
关; DTC ${ }^{\prime}{ }_{\mathrm{TRL}} 、 \mathrm{DTC}_{\mathrm{RSA}}^{\prime} 、 \mathrm{DTC}_{\mathrm{RV}}^{\prime} 、 \mathrm{DTC}_{\mathrm{RFW}}^{\prime}$ 和 $\mathrm{DTC}^{\prime}{ }_{\mathrm{RDW}}$ 均与雨养和灌溉条件下千粒重显著相关, 仅与雨养 条件下产量显著相关(表 3)。说明苗期根系性状抗旱 性与雨养条件下产量性状的相关性较高, 可以将苗 期最大根长和根生物量作为旱地育种工作中篮选产 量和抗旱性的指标。

\section{3 讨论}

\section{1 苗期根系性状与抗旱性密切相关}

根系是作物吸收水分和养分的主要器官，形态 特征直接影响水分的吸收和利用。苗期根系遗传力 高, 受环境影响较小, 正常生长条件下可以反映成 株期根系形态和根群分布, 与成株期抗旱性息息相 关 ${ }^{[5,9-13]}$ 。玉米的苗期根长、根重和根系水导等与抗 旱性极显著相关，可作为生产中篮选抗旱品种的指 标 $^{[37]}$ 。王贺正等 ${ }^{[38]}$ 证明水稻根长也可作为苗期抗旱 

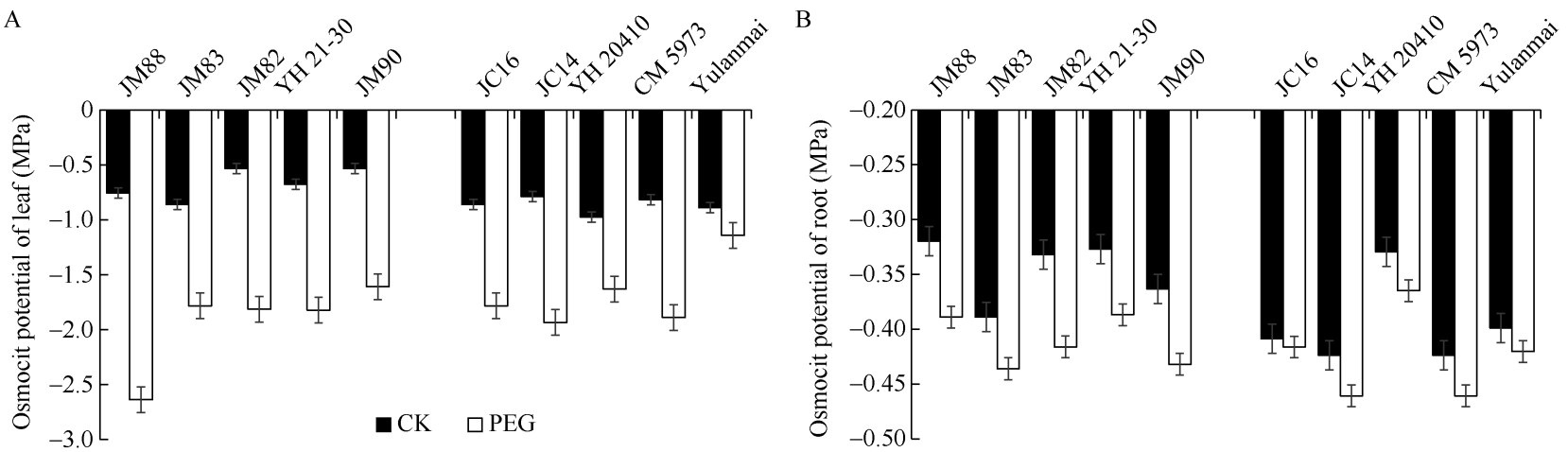

图 6 干旱胁迫下小麦幼苗渗透势

Fig. 6 Osmotic potential of wheat seedling under drought treatments

A: 叶片渗透势; B: 根系渗透势。JM88: 晋麦 88; JM83: 晋麦 83; JM82：晋麦 82; YH 21-30: 运旱 21-30; JM90: 晋麦 90; JC16: 晋春 16; JC14: 晋春 14; YH 20410: 运旱 20410; CM 5973：长麦 5973; Yulanmai: 玉兰麦。

A: osmotic potential of leaf; B: osmotic potential of root. JM88: Jinmai 88; JM83: Jinmai 83; JM82: Jinmai 82; YH 21-30: Yunhan 21-30; JM90: Jinmai 90; JC16: Jinchun 16; JC14: Jinchun 14; YH 20410: Yunhan 20410; CM 5973: Changmai 5973.

表 3 苗期根部性状抗旱性与产量相关性分析

Table 3 Correlation analysis between seedling root traits and yield-related traits

\begin{tabular}{|c|c|c|c|c|c|c|c|c|c|c|c|c|c|}
\hline \multirow[b]{2}{*}{$\mathrm{DTC}_{i}^{\prime}$} & \multirow{2}{*}{$\begin{array}{c}\text { 成株期 } \\
D \text { 值 } \\
D \text {-value at } \\
\text { adult stage }\end{array}$} & \multicolumn{6}{|c|}{ 雨养 Rain-fed } & \multicolumn{6}{|c|}{ 灌溉 Well-watered } \\
\hline & & $\begin{array}{c}\text { 株高 } \\
\mathrm{PH}\end{array}$ & $\begin{array}{l}\text { 小穗数 } \\
\text { SNPP }\end{array}$ & $\begin{array}{l}\text { 穗粒数 } \\
\text { GNPS }\end{array}$ & $\begin{array}{l}\text { 有效 } \\
\text { 分藍 } \\
\mathrm{EPT}\end{array}$ & $\begin{array}{c}\text { 千粒重 } \\
\text { TKW }\end{array}$ & $\begin{array}{l}\text { 单株 } \\
\text { 产量 } \\
\text { YPP }\end{array}$ & $\begin{array}{l}\text { 株高 } \\
\mathrm{PH}\end{array}$ & $\begin{array}{l}\text { 小穗数 } \\
\text { SNPP }\end{array}$ & $\begin{array}{c}\text { 穗粒数 } \\
\text { GNPS }\end{array}$ & $\begin{array}{l}\text { 有效 } \\
\text { 分菜 } \\
\mathrm{EPT} \\
\end{array}$ & $\begin{array}{c}\text { 千粒重 } \\
\text { TKW }\end{array}$ & $\begin{array}{c}\text { 单株产量 } \\
\text { YPP }\end{array}$ \\
\hline MRL & $0.193^{*}$ & 0.025 & -0.043 & -0.043 & 0.186 & $0.186^{*}$ & $0.189^{*}$ & -0.084 & -0.111 & $-0.163^{*}$ & 0.079 & 0.111 & -0.093 \\
\hline TRL & 0.195 & -0.059 & 0.011 & -0.046 & 0.098 & $0.181^{*}$ & $0.167^{*}$ & -0.089 & -0.024 & -0.119 & 0.049 & $0.170^{*}$ & -0.016 \\
\hline RSA & 0.114 & -0.031 & 0.071 & -0.004 & 0.112 & $0.225^{* *}$ & 0.116 & -0.034 & 0.029 & -0.111 & 0.043 & $0.206^{* *}$ & 0.011 \\
\hline RV & 0.086 & -0.004 & 0.120 & 0.068 & 0.112 & $0.201^{*}$ & $0.190^{*}$ & 0.038 & 0.097 & -0.052 & 0.024 & $0.190^{*}$ & 0.056 \\
\hline $\mathrm{RN}$ & $-0.175^{*}$ & $-0.183^{*}$ & 0.131 & 0.140 & -0.051 & -0.075 & 0.064 & -0.063 & 0.022 & 0.006 & 0.128 & 0.048 & 0.032 \\
\hline SFW & $0.172^{*}$ & 0.009 & 0.076 & -0.008 & 0.182 & $0.162^{*}$ & 0.078 & -0.045 & -0.008 & -0.123 & 0.090 & 0.112 & -0.043 \\
\hline SDW & $0.207^{* *}$ & 0.026 & 0.006 & -0.008 & 0.236 & $0.229^{* *}$ & 0.112 & -0.032 & -0.056 & -0.124 & 0.071 & 0.141 & -0.030 \\
\hline RFW & $0.175^{*}$ & 0.004 & 0.059 & 0.059 & 0.189 & $0.239^{* *}$ & $0.179^{*}$ & 0.012 & -0.019 & -0.117 & 0.089 & $0.164^{*}$ & -0.017 \\
\hline RDW & $0.184^{*}$ & 0.020 & 0.108 & 0.019 & 0.154 & $0.346^{* *}$ & $0.198^{*}$ & -0.004 & 0.019 & -0.079 & 0.072 & $0.277^{* *}$ & 0.082 \\
\hline FRSR & 0.054 & -0.007 & -0.052 & -0.016 & -0.010 & 0.061 & 0.022 & 0.082 & -0.022 & -0.008 & -0.019 & -0.002 & -0.011 \\
\hline DRSR & -0.045 & -0.039 & 0.147 & -0.019 & -0.136 & 0.114 & 0.045 & 0.049 & 0.108 & -0.007 & 0.002 & 0.147 & 0.071 \\
\hline SWLR & -0.050 & 0.004 & $0.187^{*}$ & 0.042 & -0.009 & -0.054 & 0.008 & 0.018 & 0.115 & -0.045 & 0.061 & 0.014 & -0.027 \\
\hline RWLR & 0.131 & -0.025 & -0.025 & 0.012 & 0.093 & -0.060 & -0.017 & -0.022 & -0.058 & -0.134 & 0.061 & $-0.160^{*}$ & $-0.210^{* *}$ \\
\hline
\end{tabular}

${ }^{* *}$ 与 ${ }^{*}$ 分别表示在 0.01 和 0.05 水平差异显著。缩写同表 1 。

** and ${ }^{*}$ indicate different significances at the 0.01 and 0.05 probability levels, respectively. Abbreviations in the first column are the same as those in Table 2. PH: plant weight; GNPS: grain number per spike; SNPP: spikelet number per spike; EPT: effective plant tiller; TKW: 1000-kernel weight; YPP: yield per plant. Abbreviations the same as those in Table 1.

性的形态指标; 旱育积苗一直强化育根，苗期壮根 可保证生育后期单位株高干物质重 ${ }^{[39]}$, 因此, 研究 旱胁迫下苗期根系的形态特征和生理功能是揭示种 质抗旱性的有效方法。小麦是干旱与半干旱地区的 主要作物, 发达的早期根系有利于干旱环境下水分 和养分的吸收 ${ }^{[5]}$ 。Dhanda 等 ${ }^{[26]}$ 发现小麦幼苗干旱胁 迫下, 根长、根冠比和膜渗透性表现出较大变异和 较高遗传力, 可用于预测植株的耐旱性。本文利用
PEG 模拟旱胁迫探索小麦苗期根系性状的响应，发 现总根长(TRL)、根冠比(FRSR 和 DRSR)和地上部 生物量(SFW 和 SDW)对水分胁迫敏感, 其次为根表 面积(RSA)、根体积(RV)和根生物量(RFW 和 RDW), 最大根长 $(\mathrm{MRL})$ 和平均根数 $(\mathrm{RN})$ 对水分胁迫敏感性 较低。目前本文考察了不同品种根系对水分胁迫的 形态响应, 后期将从遗传途径和吸水效率进行研究, 挖掘调控根系性状的显著位点, 进一步解析小麦根 
系抗旱特性的机理。

\section{2 苗期根系形态影响产量性状}

苗期初生根在整个生育期均发挥重要作用, 形 成的深层根系在干旱环境下能有效利用深土层养分 和水分 ${ }^{[13,40]}$, 进而影响产量性状。半干旱地区小麦苗 期多处于干旱少雨的秋冬季节 ${ }^{[41]}$, 土壤下层充足的 水分能保障初生根的生长, 水分不足则会减少次生 根的生成, 影响根系分布。此外, 苗期根系活力直接 关系到成株期地上部的生长发育 ${ }^{[5-6,42]}$, 这是小麦苗 期的根系形态建成对产量贡献的关键 ${ }^{[43]}$ 。目前苗期主 要用反复干旱存活率或 PEG 模拟胁迫法鉴定种质的 抗旱性, 这类方法能体现苗期生理上抗旱性, 也是苗 期高抗品种含有水地品种的原因。在农业生产中, 作 物抗旱性的评价一般以稳产为前提, 牺牲产量提高 存活力的种质是不可取的, 人为设定的成株期抗旱 性评价指标往往重点关注产量。李龙等 ${ }^{[44]}$ 发现·晋麦 47 等旱地高产稳产品种的苗期抗旱性一般, 得出苗 期抗旱性与成株期抗旱性不相关结论, 可能是苗期 反复干旱法仅考虑了胁迫下存活率, 忽略了根系在 生长发育后期对籽粒形成的贡献。本文分析了苗期根 系性状归一化后的抗旱系数与产量性状的关系, 发 现最大根长(MRL)、总根长(TRL)、根体积 $(R V)$ 和根 生物量(RFW 和 RDW)的抗旱特性与雨养下千粒重和 产量呈显著正相关, 且最大根长(MRL)和根生物量 (RFW 和 RDW)与成株期抗旱性显著正相关, 可以将 苗期最大根长、根生物量等作为旱地育种中篮选抗性 和产量的早期指示指标。目前应用单株产量进行了研 究, 生产条件下群体产量与稀播下个体产量有时存 在差异, 对篮选指标的效应会造成偏差, 随着人们对 个体-群体及个体竞争对产量形成影响机制的认识, 这种偏差将会更好的解决。

3.3 山西小麦根系变化揭示半干旱地区根系演 变趋势

小麦农艺性状演变规律研究历来备受重视。

自 20 世纪 40 年代以来, 在全国范围内实现了 6 9 次小麦品种更换, 每次品种更换不仅产量有了很 大提高, 而且品种综合性状也会改善。目前不同省 份关于株高、叶片、抽穗期、产量和品质等性状 的演变规律已较为清楚, 根系是小麦地上部分的 根本, 其形态和生理特征的研究较为欠缺, 关于 根系演变趋势和特点尚有不同看法。Zhu 等 ${ }^{[29]}$ 选 择中国西北地区广泛种植的 8 个品种, 证明现代 品种的根系比早期品种窄, 具有扎根深和横向分
布少的特点。张荣等 ${ }^{[30]}$ 研究黄土高原 5 个春麦品 种的演变趋势是根系不断减小。田中伟等 ${ }^{[31]}$ 利用 5 个品种研究了长江中下游地区根系更替, 发现根 系总根长、表面积和根体积显著增大。不同研究 结论存在差异, 一是利用的材料份数少导致偶然 性过大, 另一方面是采用长江中下游麦区和西南 麦区的小麦品种, 这些地区水分充足, 无法客观 反映根系对水分胁迫响应。

本文采用可代表半干旱地区的山西小麦为材料, 系统研究了苗期根系的演变趋势, 发现苗期最大根 长随年代略降低, 而最大根长的生理抗旱性却一直 增加; 苗期总根长、根表面积、根体积和根生物量 等性状随年代基本表现出先增后降趋势, 但根系性 状的抗旱系数则表现为先降后升, 以 20 世纪 80 年代 和 90 年代的品种性状值最大。可能是 90 年代以前品 种改良主要以提高根系生物量, 增加水肥吸收, 进 而提高产量, 在这个过程中忽略了品种生理抗旱性; 而90年代后产量和地下生物量达到一定平衡, 产量 的提高依赖地下根系几余减少、构型优化、水肥利 用效率和抗旱性的提高。根冠比过大会影响地上部 生物学产量和经济产量的形成, 造成根系冗余, 因 此适宜的根系将会是半干旱区小麦育种的重要指标, 这与 Sun 等 ${ }^{[14]}$ 提出的干旱与半干旱地区小麦根系的 生态预测一致。可见在今后干旱与半干旱地区的品 种选育过程中应人为调控根系的大小, 通过提高水 分利用率培育抗旱节水的优良品种, 从而促进小麦 抗旱节水的遗传改良。

\section{4 结论}

山西小麦苗期根系性状多样性丰富，总根长、 根表面积、根体积、平均根数及根生物量随年代表 现出明显的先增后降现象, 各性状抗旱系数整体上 呈先降后增的趋势。干旱胁迫抑制了小麦苗期根系 生长, 不同根系性状对旱胁迫的响应存在差异, 总 根长对水分胁迫最敏感, 其次为根体积、根表面积 和根生物量, 最大根长和平均根数敏感性最低。最 大根长和根生物量与雨养条件下成株期产量和抗性 显著相关, 可作为旱地育种中抗旱高产优异种质的 早期筛选指标。

致谢：在材料征集的过程中得到了山西省农业科学 院柴永峰、任杰成、张晓军、张东旭、间金龙、卜 斌和任永康等老师, 以及中国农业科学院作物科学 研究所景薊莲研究员的大力协助, 谨致热忱! 


\section{References}

[1] Manschadi A M, Christopher J, Devoil P, Hammer G L. The role of root architectural traits in adaptation of wheat to water-limited environments. Funct Plant Biol, 2006, 33: 823-837.

[2] Berry P M, Sylvester-Bradly R, Berry S. Ideotype design for lodging-resistant wheat. Euphytica, 2007, 154: 165-179.

[3] Atkinson J A, Wingen L U, Griffiths M, Pound M P, Gaju O, Foulkes M J, Gouis J L, Griffiths S, Bennett M J, King J, Wells D M. Phenotyping pipeline reveals major seedling root growth QTL in hexaploid wheat. $J$ Exp Bot, 2015, 66: 2283-2292.

[4] Veronica M R, Jorge B V, Luis L B, Rafael J L B. Monitoring wheat root development in a rainfed vertisol: tillage effect. Eur $J$ Agron, 2010, 33: 182-187.

[5] Ibrahim S E, Schubert A, Pillen K, Léon J. QTL analysis of drought tolerance for seedling root morphological traits in an advanced backcross population of spring wheat. Int $J$ Agric Sci, 2012, 2: 619-629.

[6] Placido D F, Campbell M T, Folsom J J, Cui X, Kruger G R, Stephen B P, Walia H. Introgression of novel traits from a wild wheat relative improves drought adaptation in wheat. Plant Physiol, 2013, 161: 1806-1819.

[7] Feng S W, Gu S B, Zhang H B, Wang D. Root vertical distribution is important to improve water use efficiency and grain yield of wheat. Field Crops Res, 2017, 214: 131-141.

[8] Zobel R W, Wright S F. Primary and secondary root systems. In: Roots and Soil Management: Interactions between Roots and the Soil. ASA, CSSA, and SSSA, Madison, WI, 2005. pp 3-14.

[9] Cane M A, Maccaferri M, Nazemi G, Salvi S, Francia R, Colalonga $\mathrm{C}$, Roberto $\mathrm{T}$. Association mapping for root architectural traits in durum wheat seedlings as related to agronomic performance. Mol Breed, 2014, 34: 1629-1645.

[10] Liu X L, Li R Z, Chang X P, Jing R L. Mapping QTLs for seedling root traits in a doubled haploid wheat population under different water regimes. Euphytica, 2013, 189: 51-66.

[11] Kabir M R, Liu G, Guan P F, Wang F, Khan A A, Ni Z F, Yao Y Y, Hu Z R, Xin M M, Peng H R, Sun Q X. Mapping QTLs associated with root traits using two different populations in wheat (Triticum aestivum L.). Euphytica, 2015, 206: 175-190.

[12] Xie Q, Fernando K M C, Mayes S, Sparkes D L. Identifying seedling root architectural traits associated with yield and yield components in wheat. Ann Bot, 2017, 119: 1115-1129.

[13] 苗青霞, 方燕, 陈应龙. 小麦根系特征对干旱胁迫的响应. 植 物学报, 2019, 54: 652-661.

Miao Q X, Fang Y, Chen Y L. Studies in the responses of wheat root traits to drought stress. Chin Bull Bot, 2019, 54: 652-661 (in Chinese with English abstract).

[14] Sun Y Y, Zhang S Q, Chen W. Root traits of dryland winter wheat (Triticum aestivum L.) from the 1940s to the 2010s in Shaanxi province, China. Sci Rep, 2020, 10: 5328.

[15] An D G, Su J Y, Liu Q Y, Zhu Y G, Tong Y P, Li J M, Jing R L, Li B, Li Z S. Mapping QTLs for nitrogen uptake in relation to the early growth of wheat (Triticum aestivum L.). Plant Soil, 2006, 284: 73-84.

[16] Fan X L, Zhang W, Zhang N, Chen M, Zheng S S, Zhao C H, Han J, Liu J J, Zhang X L, Song L Q, Ji J, Liu X G, Ling H Q,
Tong Y P, Cui F, Wang T, Li J M. Identification of QTL regions for seedling root traits and their effect on nitrogen use efficiency in wheat (Triticum aestivum L.). Theor Appl Genet, 2018, 131: 2677-2698.

[17] Ayalew H, Ma X, Yan G. Screening wheat (Triticum spp.) genotypes for root length under contrasting water regimes: potential sources of variability for drought resistance breeding. J Agron Crop Sci, 2015, 201: 189-194.

[18] Christopher J, Christopher M J, Jennings R, Jones S, Fletcher S, Borrell A, Manschadi A M, Jordan D, Mace E, Hammer G. QTL for root angle and number in a population developed from bread wheats (Triticum aestivum) with contrasting adaptation to waterlimited environments. Theor Appl Genet, 2013, 126: 1563-1574.

[19] Bai C H, Liang Y L, Hawkesford M J. Identification of QTLs associated with seedling root traits and their correlation with plant height in wheat. $J$ Exp Bot, 2013, 64: 1745-1753.

[20] Hamada A, Nitta M, Nasuda S, Kato K, Fujita M, Matsunaka H, Okumoto Y. Novel QTLs for growth angle of seminal roots in wheat (Triticum aestivum L.). Plant Soil, 2012, 354: 395-405.

[21] Cao P, Ren Y Z, Zhang K P, Teng W, Zhao X Q, Dong Z Y, Liu X, Qin H J, Li Z S, Wang D W, Tong Y P. Further genetic analysis of a major quantitative trait locus controlling root length and related traits in common wheat. Mol Breed, 2014, 33: 975-985.

[22] 肖永贵, 路亚明, 闻伟锷, 陈新民, 夏先春, 王德森, 李思敏, 童依平, 何中虎. 小麦骨干亲本京 411 及衍生品种苗期根部性 状的遗传. 中国农业科学, 2014, 47: 2916-2926.

Xiao Y G, Lu Y M, Wen W E, Chen X M, Xia X C, Wang D S, Li $\mathrm{S}$ M, Tong Y P, He Z H. Genetic contribution of seedling root traits among elite wheat parent Jing 411 to its derivatives. Sci Agric Sin, 2014, 47: 2916-2926 (in Chinese with English abstract).

[23] 景苾莲, 昌小平, 朱志华, 胡荣海. 小麦幼苗根系形态与反复 干旱存活率的关系. 西北植物学报, 2002, 22: 243-249.

Jing R L, Chang X P, Zhu Z H, Hu R H. Relationship between root morphology of wheat (T. aestivum) and survival percentage under repeated drought condition. Acta Bot Boreali-Occident Sin, 2002, 22: 243-249 (in Chinese with English abstract).

[24] 马富举, 李丹丹, 蔡剑, 姜东, 曹卫星, 戴廷波. 干旱胁迫对 小麦幼苗根系生长和叶片光合作用的影响. 应用生态学报, 2012, 23: 724-730.

Ma F J, Li D D, Cai J, Jiang D, Cao W X, Dai T B. Responses of wheat seedlings root growth and leaf photosynthesis to drought stress. Chin J Appl Ecol, 2012, 23: 724-730 (in Chinese with English abstract).

[25] Dhanda S S, Sethi G S, Behl R K. Indices of drought tolerance in wheat genotypes at early stages of plant growth. J Agron Crop Sci, 2004, 190: 6-12.

[26] Landjeva S, Neumann K, Lohwasser U, Börner A. Molecular mapping of genomic regions associated with wheat seedling growth under osmotic stress. Biol Plant, 2008, 52: 259-266.

[27] 周晓果, 景惢莲, 郝转芳, 昌小平, 张正斌. 小麦幼苗根系性 状的 QTL 分析. 中国农业科学, 2005, 38: 1951-1957.

Zhou X G, Jing R L, Hao Z F, Chang X P, Zhang Z B. Mapping QTL for seedling root traits in common wheat. Sci Agric Sin, 2005, 38: 1951-1957 (in Chinese with English abstract). 
[28] 胡雯媚, 王思宇, 樊高琼, 刘运军, 郑文, 王强生, 马宏亮. 西 南麦区小麦品种苗期抗旱性鉴定及其指标篮选. 麦类作物学 报, 2016, 36: 182-193.

Hu W M, Wang S Y, Fan G Q, Liu Y J, Zheng W, Wang Q S, Ma $\mathrm{H} \mathrm{L}$. Analysis on the drought resistance and screening of drought resistance appraisal indexes of wheat cultivars in seedling stage in southwest area. J Triticeae Crops, 2016, 36: 182-189 (in Chinese with English abstract).

[29] Zhu Y H, Weiner J, Yu M X, Li F M. Evolutionary agroecology: trends in root architecture during wheat breeding. Evol Appl, 2019, 12: 733-743.

[30] 张荣, 张大勇. 半干旱区春小麦不同年代品种根系生长几余 的比较实验研究. 植物生态学报, 2000, 24: 298-303.

Zhang R, Zhang D Y. A comparative study on root redundancy in spring wheat varieties released in different years in semi-arid area. Chin J Plant Ecol, 2000, 24: 298-303 (in Chinese with English abstract).

[31] 田中伟, 樊永惠, 殷美, 王方瑞, 蔡剑, 姜东, 戴廷波. 长江中 下游小麦品种根系改良特征及其与产量的关系. 作物学报, 2015, 41: 613-622.

Tian Z W, Fan Y H, Yin M, Wang F R, Cai J, Jiang D, Dai T B. Genetic improvement of root growth and its relationship with grain yield of wheat cultivars in the middle-lower Yangtze river. Acta Agron Sin, 2015, 41: 613-622 (in Chinese with English abstract).

[32] 唐水, 王晓毅, 侯㑆, 侯亮亮. 山西晋中小南庄墓地人骨的 C、 $\mathrm{N}$ 稳定同位素:试析小麦在山西的推广. 人类学学报, 2018,37 : 318-330.

Tang M, Wang X Y, Hou K, Hou L L. Carbon and nitrogen stable isotope of the human bones from the Xiaonanzhuang cemetery, Jinzhong, Shanxi: A preliminary study on the expansion of wheat in ancient Shanxi, China. Acta Anthropol Sin, 2018, 37: 318-330 (in Chinese with English abstract).

[33] 赵佳佳, 乔玲, 郑兴卫, 李晓华, 曹勇, 马小飞, 杨斌, 姬虎太, 乔麟轶, 郑军, 张建诚. 山西小麦育成品种品质性状及 HMW-GS 组成演变分析. 植物遗传资源学报, 2018, 19: 1126-1137.

Zhao J J, Qiao L, Zheng X W, Li X H, Cao Y, Ma X F, Yang B, Ji H T, Qiao L Y, Zheng J, Zhang J C. Variation of quality-related traits and HMW-GS of wheat varieties in Shanxi province. $J$ Plant Genet Resour, 2018, 19: 1126-1137 (in Chinese with English abstract).

[34] 吕学莲, 白海波, 惠建, 田小燕, 杨宸刚, 马斯霜, 蔡正云, 李 树华. 籼粳稻杂交衍生 RIL 系的苗期抗旱性评价. 植物遗传资 源学报, 2019, 20: 556-563

Lyu X L, Bai H B, Hui J, Tian X Y, Yang C G, Ma S S, Cai Z Y, Li SH. Evaluation of seedling drought resistance of RIL derived from indica rice and japonica rice. J Plant Genet Resour, 2019,
20: 556-563 (in Chinese with English abstract).

[35] Ming D F, Pei Z F, Naeem M S, Gong H J, Zhou W J. Silicon alleviates PEG-induced water-deficit stress in upland rice seedlings by enhancing osmotic adjustment. J Agron Crop Sci, 2012, 198: 14-26.

[36] Blum A. Osmotic adjustment is a prime drought stress adaptive engine in support of plant production. Plant Cell Environ, 2017, 40: 4-10.

[37] 慕自新, 张岁岐, 梁爱华, 梁宗锁. 玉米整株根系水导与其表 型抗旱性的关系. 作物学报, 2005, 31: 203-208.

Mu Z X, Zhang S Q, Liang A H, Liang Z S. Relationship between maize root hydraulic conductivity and drought resistance. Acta Agron Sin, 2005, 31: 203-208 (in Chinese with English abstract).

[38] 王贺正, 李艳, 马均, 张荣萍, 李旭毅, 汪仁全. 水稻苗期抗 旱性指标的節选. 作物学报, 2007, 33: 1523-1529.

Wang H Z, Li Y, Ma J, Zhang R P, Li X Y, Wang R Q. Screening indexes of drought resistance during seedling stage in rice. Acta Agron Sin, 2007, 33: 1523-1529 (in Chinese with English abstract).

[39] 赵言文, 丁艳锋, 陈留根, 黄丕生. 水稻旱育秧苗抗旱生理特 性研究. 中国农业科学, 2001, 34: 283-291.

Zhao Y W, Ding Y F, Chen L G, Huang P S. Physiological characteristics of drought resistance of rice dry nursery seedlings. Sci Agric Sin, 2001, 34: 283-291 (in Chinese with English abstract).

[40] Liao M, Fillery I, Palta J. Early vigorous growth is a major factor influencing nitrogen uptake in wheat. Funct Plant Biol, 2004, 31: 121-129.

[41] 陈成升, 谢志霞, 刘小京. 旱盐互作对冬小麦幼苗生长及其抗 逆生理特性的影响. 应用生态学报, 2009, 20: 811-816.

Chen C S, Xie Z X, Liu X J. Interactive effects of drought and salt stresses on winter wheat seedling growth and physio logical characteristics of stress resistance. Chin J Appl Ecol, 2009, 20: 811-816 (in Chinese with English abstract).

[42] 魏道智, 宁书菊, 林文雄. 小麦根系活力变化与叶片衰老的研 究. 应用生态学报, 2004, 15: 1565-1569.

Wei D Z, Ning S J, Lin W X. Relationship between wheat root activity and leaf senescence. Chin J Appl Ecol, 2004, 15: 1565-1569 (in Chinese with English abstract).

[43] Sandhu N, Subedi S R, Singh V K, Sinha P, Kumar S, Singh S P, Ghimire S K, Pandey M, Yadaw R B, Varshney R K, Kumar A. Deciphering the genetic basis of root morphology, nutrient uptake, yield, and yield-related traits in rice under dry direct-seeded cultivation systems. Sci Rep, 2019, 9: 9334.

[44] 李龙, 毛新国, 王景一, 昌小平, 柳玉平, 景药莲. 小麦种质 资源抗旱性鉴定评价. 作物学报, 2018, 44: 988-999.

Li L, Mao X G, Wang J Y, Chang X P, Liu Y P, Jing R L. Drought tolerance evaluation of wheat germplasm resources. Acta Agron Sin, 2018, 44: 988-999 (in Chinese with English abstract). 
附表 1 山西小麦品种(系)及其审定年限

Table S1 Wheat cultivars bred in Shanxi province and the approval of the year

\begin{tabular}{|c|c|c|c|c|c|c|c|}
\hline $\begin{array}{l}\text { 编号 } \\
\text { No. }\end{array}$ & $\begin{array}{c}\text { 品种 } \\
\text { Variety }\end{array}$ & $\begin{array}{l}\text { 年份 } \\
\text { Year }\end{array}$ & $\begin{array}{l}\text { 类型 } \\
\text { Type }\end{array}$ & $\begin{array}{l}\text { 编号 } \\
\text { No. }\end{array}$ & $\begin{array}{c}\text { 品种 } \\
\text { Variety }\end{array}$ & $\begin{array}{l}\text { 年份 } \\
\text { Year }\end{array}$ & $\begin{array}{l}\text { 类型 } \\
\text { Type }\end{array}$ \\
\hline 1 & 晋麦 1 号 Jinmai 1 & 1973 & 旱 DC & 121 & 晋麦 88 Jinmai 88 & 2009 & 旱 DC \\
\hline 2 & 晋麦 5 号 Jinmai 5 & 1973 & 旱 DC & 122 & 山农 129 Shannong 129 & 2009 & 水 IC \\
\hline 3 & 晋春 3 号 Jinchun 3 & 1974 & 旱 DC & 123 & 太 13606 Tai 13606 & 2009 & 水 IC \\
\hline 4 & 晋麦 11 Jinmai 11 & 1980 & 水 $\mathrm{IC}$ & 124 & 长麦 5973 Changmai 5973 & 2009 & 水 IC \\
\hline 5 & 晋麦 12 Jinmai 12 & 1980 & 水 $\mathrm{IC}$ & 125 & 长 5222 Chang 5222 & 2009 & 水 IC \\
\hline 6 & 晋麦 13 Jinmai 13 & 1980 & 旱 DC & 126 & 晋麦 88 Jinmai 88 & 2009 & 旱 DC \\
\hline 7 & 晋麦 16 Jinmai 16 & 1982 & 旱 DC & 127 & NC206 & 2009 & 水 IC \\
\hline 8 & 晋麦 17 Jinmai 17 & 1982 & 旱 DC & 128 & 临 Y7287 Lin Y7287 & 2009 & 水 IC \\
\hline 9 & 晋麦 18 Jinmai 18 & 1983 & 水 $\mathrm{IC}$ & 129 & 晋春 16 Jinchun 16 & 2009 & 水 IC \\
\hline 10 & 晋麦 19 Jinmai 19 & 1983 & 水 IC & 130 & 长麦 6135 Changmai 6135 & 2010 & 水 IC \\
\hline 11 & 晋麦 20 Jinmai 20 & 1984 & 水 IC & 131 & 临远 8 号 Linyuan 8 & 2010 & 水 IC \\
\hline 12 & 晋麦 21 Jinmai 21 & 1985 & 水 IC & 132 & 长麦 251 Changmai 251 & 2011 & 水 IC \\
\hline 13 & 晋麦 22 Jinmai 22 & 1985 & 旱 DC & 133 & 长 8744 Chang 8744 & 2011 & 旱 DC \\
\hline 14 & 晋麦 23 Jinmai 23 & 1985 & 水 IC & 134 & 晋麦 90 Jinmai 90 & 2011 & 旱 DC \\
\hline 15 & 晋麦 24 Jinmai 24 & 1987 & 水 $\mathrm{IC}$ & 135 & 晋麦 91 Jinmai 91 & 2011 & 旱 DC \\
\hline 16 & 晋麦 25 Jinmai 25 & 1988 & 水 $\mathrm{IC}$ & 136 & 运旱 805 Yunhan 805 & 2011 & 旱 DC \\
\hline 17 & 晋麦 9 号 Jinmai 9 & 1988 & 水 IC & 137 & 尧麦 16 Yaomai 16 & 2011 & 水 IC \\
\hline 18 & 晋麦 27 Jinmai 27 & 1989 & 旱 DC & 138 & 舜麦 1718 Shunmai 1718 & 2011 & 水 IC \\
\hline 19 & 晋麦 28 Jinmai 28 & 1989 & 旱 DC & 139 & 晋麦 92 Jinmai 92 & 2013 & 旱 DC \\
\hline 20 & 晋麦 29 Jinmai 29 & 1989 & 旱 DC & 140 & 晋太 182 Jintai 182 & 2013 & 水 IC \\
\hline 21 & 晋麦 30 Jinmai 30 & 1990 & 水 IC & 141 & 长 4853 Chang 4853 & 2013 & 旱 DC \\
\hline 22 & 晋麦 31 Jinmai 31 & 1990 & 水 IC & 142 & 晋麦 94 Jinmai 94 & 2014 & 水 IC \\
\hline 23 & 晋麦 32 Jinmai 32 & 1990 & 水 IC & 143 & 晋麦 95 Jinmai 95 & 2014 & 水 IC \\
\hline 24 & 晋麦 33 Jinmai 33 & 1990 & 旱 DC & 144 & 晋麦 96 Jinmai 96 & 2014 & 水 IC \\
\hline 25 & 晋麦 35 Jinmai 35 & 1990 & 水 $\mathrm{IC}$ & 145 & 晋太 102 Jintai 102 & 2014 & 水 IC \\
\hline 26 & 晋麦 36 Jinmai 36 & 1991 & 旱 DC & 146 & 晋麦 97 Jinmai 97 & 2014 & 旱 DC \\
\hline 27 & 晋麦 37 Jinmai 37 & 1991 & 水 $\mathrm{IC}$ & 147 & 晋麦 98 Jinmai 98 & 2014 & 旱 DC \\
\hline 28 & 晋麦 38 Jinmai 38 & 1991 & 旱 DC & 148 & 太春 3473 Taichun 3473 & 2014 & 水 IC \\
\hline 29 & 晋麦 39 Jinmai 39 & 1991 & 旱 DC & 149 & 晋麦 99 Jinmai 99 & 2015 & 旱 DC \\
\hline 30 & 晋麦 40 Jinmai 40 & 1991 & 旱 DC & 150 & 良星 67 Liangxing 67 & 2016 & 水 IC \\
\hline 31 & 晋麦 41 Jinmai 41 & 1992 & 水 $\mathrm{IC}$ & 151 & 运旱 137 Yunhan 137 & 2016 & 旱 DC \\
\hline 32 & 晋麦 42 Jinmai 42 & 1992 & 旱 DC & 152 & 太 113 Tai 113 & 2016 & 水 IC \\
\hline 33 & 晋麦 44 Jinmai 44 & 1992 & 旱 DC & 153 & 晋作 80 Jinzuo 80 & 2016 & 水 IC \\
\hline 34 & 晋麦 43 Jinmai 43 & 1992 & 旱 DC & 154 & 晋太 114 Jintai 114 & 2016 & 水 IC \\
\hline 35 & 晋麦 45 Jinmai 45 & 1993 & 水 IC & 155 & 长 6794 Chang 6794 & 2016 & 水 IC \\
\hline 36 & 晋麦 46 Jinmai 46 & 1994 & 旱 DC & 156 & 晋太 1310 Jintai 1310 & 2016 & 旱 DC \\
\hline 37 & 晋麦 47 Jinmai 47 & 1995 & 旱 DC & 157 & 长 6990 Chang 6990 & 2016 & 旱 DC \\
\hline 38 & 晋麦 48 Jinmai 48 & 1995 & 水 $\mathrm{IC}$ & 158 & 中麦 247 Zhongmai 247 & 2016 & 水 IC \\
\hline 39 & 晋麦 49 Jinmai 49 & 1996 & 水 IC & 159 & 润麦 2 号 Runmai 2 & 2016 & 旱 DC \\
\hline 40 & 晋麦 50 Jinmai 50 & 1996 & 旱 DC & 160 & 长 6197 Chang 6197 & 2017 & 旱 DC \\
\hline 41 & 晋麦 51 Jinmai 51 & 1996 & 旱 DC & 161 & 长 7080 Chang 7080 & 2017 & 旱 DC \\
\hline 42 & 晋麦 52 Jinmai 52 & 1996 & 水 $\mathrm{IC}$ & 162 & 临 Y8161 Lin Y8161 & 2017 & 旱 DC \\
\hline 43 & 晋麦 53 Jinmai 53 & 1996 & 水、旱 $\mathrm{IC}, \mathrm{DC}$ & 163 & 晋太 141 Jintai 141 & 2017 & 旱 DC \\
\hline 44 & 晋春 13 Jinchun 13 & 1996 & 水 IC & 164 & 晋太 146 Jintai 146 & 2017 & 水 IC \\
\hline
\end{tabular}


(续附表 1)

\begin{tabular}{|c|c|c|c|c|c|c|c|}
\hline 编号 & 品种 & 年份 & 类型 & 编号 & 品种 & 年份 & 类型 \\
\hline No. & Variety & Year & Type & No. & Variety & Year & Type \\
\hline 45 & 晋麦 54 Jinmai 54 & 1997 & 旱 DC & 165 & 太 412 Tai 412 & 2017 & 水 IC \\
\hline 46 & 黑小麦 76 Heixiaomai 76 & 1997 & 水 IC & 166 & 石农 086 Shinong 086 & 2017 & 水 IC \\
\hline 47 & 晋麦 56 Jinmai 56 & 1998 & 旱 DC & 167 & 翔麦 23 Xiangmai 23 & 2017 & 水 IC \\
\hline 48 & 晋麦 57 Jinmai 57 & 1998 & 旱 DC & 168 & 运旱 139-2 Yunhan 139-2 & 2017 & 旱 DC \\
\hline 49 & 晋麦 58 Jinmai 58 & 1998 & 水 IC & 169 & 翔麦 8156 Xiangmai 8156 & 2017 & 旱 DC \\
\hline 50 & 晋麦 59 Jinmai 59 & 1998 & 旱 DC & 170 & 晋麦 104 Jinmai 104 & 2017 & 旱 DC \\
\hline 51 & 晋麦 60 Jinmai 60 & 1999 & 旱 DC & 171 & 晋春 17 Jinchun 17 & 2017 & 水 IC \\
\hline 52 & 晋麦 61 Jinmai 61 & 1999 & 旱 DC & 172 & 鲁科 298 Luke 298 & 2018 & 水 $\mathrm{IC}$ \\
\hline 53 & 晋麦 62 Jinmai 62 & 1999 & 水 IC & 173 & 太 1305 Tai 1305 & 2018 & 旱 DC \\
\hline 54 & 晋麦 63 Jinmai 63 & 1999 & 旱 DC & 174 & 运 14 观 74 Yun 14 guan 74 & 2018 & 水 $\mathrm{IC}$ \\
\hline 55 & 晋春 14 Jinchun 14 & 1999 & 水 IC & 175 & 晋麦 101 Jinmai 101 & 2018 & 旱 DC \\
\hline 56 & 晋麦 65 Jinmai 65 & 2000 & 水 IC & 176 & 晋麦 102 Jinmai 102 & 2018 & 旱 DC \\
\hline 57 & 晋麦 66 Jinmai 66 & 2000 & 水 IC & 177 & 运旱 1512 Yunhan 1512 & 2018 & 旱 DC \\
\hline 58 & 晋麦 67 Jinmai 67 & 2000 & 水 IC & 178 & 临旱 9 号 Linhan 9 & 2018 & 旱 DC \\
\hline 59 & 晋麦 68 Jinmai 68 & 2000 & 旱 DC & 179 & 沃麦 323 Womai 323 & 2018 & 旱 DC \\
\hline 60 & 晋麦 70 Jinmai 70 & 2001 & 旱 DC & 180 & 金麦 919 Jinmai 9191 & 2018 & 旱 DC \\
\hline 61 & 晋麦 71 Jinmai 71 & 2001 & 水 IC & 181 & 长 6789 Chang 6789 & 2018 & 水 IC \\
\hline 62 & 晋麦 72 Jinmai 72 & 2001 & 水 IC & 182 & 运旱 1411-2 Yunhan 1411-2 & 2018 & 旱 DC \\
\hline 63 & 晋麦 73 Jinmai 73 & 2002 & 旱 DC & 183 & 太麦 101 Taimai 101 & 2018 & 水 IC \\
\hline 64 & 晋麦 74 Jinmai 74 & 2002 & 水 IC & 184 & 晋太 1510 Jintai 1510 & 2018 & 旱 DC \\
\hline 65 & 晋麦 75 Jinmai 75 & 2002 & 水 IC & 185 & 长麦 3897 Changmai 3897 & 2018 & 旱 DC \\
\hline 66 & 临汾 615 Linfen 615 & 2002 & 水 IC & 186 & 运黑 14207 Yunhei 14207 & 2018 & 水 IC \\
\hline 67 & 运引 1 号 Yunyin 1 & 2002 & 水 IC & 187 & 运黑 161 Yunhei 161 & 2018 & 水 IC \\
\hline 68 & 晋农 207 Jinnong 207 & 2002 & 水 IC & 188 & 运糯 32 Yunnuo 32 & 2018 & 水 $\mathrm{IC}$ \\
\hline 69 & 中旱 110 Zhonghan 110 & 2002 & 旱 DC & 189 & 临 7006 Lin 7006 & 2018 & 水 IC \\
\hline 70 & 长 6878 Chang 6878 & 2002 & 旱 DC & 190 & 临 Y8012 Lin Y8012 & 2018 & 水 $\mathrm{IC}$ \\
\hline 71 & 晋太 170 Jintai 170 & 2002 & 旱 DC & 191 & 中麦 110 Zhongmai 110 & 2019 & 水 IC \\
\hline 72 & 长治 5608 Changzhi 5608 & 2002 & 旱 DC & 192 & 龙麦 1 号 Longmai 1 & 2019 & 水 IC \\
\hline 73 & 临优 145 Linyou 145 & 2003 & 水 IC & 193 & 晋麦 105 Jinmai 105 & 2019 & 旱 DC \\
\hline 74 & 临汾 138 Linfen 138 & 2003 & 水 IC & 194 & ZM148 & 2019 & 水 $\mathrm{IC}$ \\
\hline 75 & 长 6154 Chang 6154 & 2003 & 旱 DC & 195 & 长 5638 Chang 5638 & 2019 & 水 IC \\
\hline 76 & $\begin{array}{l}\text { 河东 TX-006 } \\
\text { Hedong TX-006 }\end{array}$ & 2003 & 旱 DC & 196 & 晋太 1508 Jintai 1508 & 2019 & 水 IC \\
\hline 77 & 晋太 65 Jintai 65 & 2003 & 水 IC & 197 & 太麦 103 Taimai 103 & 2019 & 水 $\mathrm{IC}$ \\
\hline 78 & 运旱 21-30 Yunhan 21-30 & 2003 & 旱 DC & 198 & 临研 151 Linyan 151 & 2019 & 水 $\mathrm{IC}$ \\
\hline 79 & 临丰 3 号 Linfeng 3 & 2004 & 旱 DC & 199 & 气死风 Qisifeng & - & 地方种 Landrace \\
\hline 80 & 临远 3158 Linyuan 3158 & 2004 & 水 IC & 200 & 红和尚 Hongheshang & - & 地方种 Landrace \\
\hline 81 & 临抗 11 Linkang 11 & 2004 & 旱 DC & 201 & 西安麦 Xianmai & - & 地方种 Landrace \\
\hline 82 & 泽优 2 号 Zeyou 2 & 2004 & 旱 DC & 202 & 笨麦 Benmai & - & 地方种 Landrace \\
\hline 83 & 冬黑 1 号 Donghei 1 & 2004 & 水 IC & 203 & 白壳红 Baikehong & - & 地方种 Landrace \\
\hline 84 & 运黑 28 Yunhei 28 & 2004 & 水 IC & 204 & 红水麦 Hongshuimai & - & 地方种 Landrace \\
\hline 85 & 冬黑 10 号 Donghei 10 & 2004 & 旱 DC & 205 & 金裹银 Jinguoyin & - & 地方种 Landrace \\
\hline 86 & 运麦 2064 Yunmai 2064 & 2004 & 水 IC & 206 & 游白兰 Youbailan & - & 地方种 Landrace \\
\hline 87 & 吕旱 1608 Lyuhan 1608 & 2004 & 旱 DC & 207 & 白线麦 Baixianmai & - & 地方种 Landrace \\
\hline 88 & 晋春 15 Jinchun 15 & 2004 & 水 IC & 208 & 白梗茬 Baigengcha & - & 地方种 Landrace \\
\hline
\end{tabular}




\begin{tabular}{|c|c|c|c|c|c|c|c|}
\hline 编号 & 品种 & 年份 & 类型 & 编号 & 品种 & 年份 & 类型 \\
\hline No. & Variety & Year & Type & No. & Variety & Year & \\
\hline 89 & 临优 2018 Linyou 2018 & 2005 & 水 IC & 209 & 新城雪里梅 Xinchengxuelimei & - & 地方种 Landrace \\
\hline 90 & 临优 2069 Linyou 2069 & 2005 & 水 $\mathrm{IC}$ & 210 & 白山麦 Baishanmai & - & 地方种 Landrace \\
\hline 91 & 运旱 2335 Yunhan 2335 & 2005 & 旱 DC & 211 & 白火麦 Baihuomai & - & 地方种 Landrace \\
\hline 92 & 长 6359 Chang 6359 & 2005 & 旱 DC & 212 & 白三月黄 Baisanyuehuang & - & 地方种 Landrace \\
\hline 93 & 长麦 5079 Changmai 5079 & 2005 & 旱 DC & 213 & 大白麦 Dabaimai & - & 地方种 Landrace \\
\hline 94 & 长 6452 Chang 6452 & 2005 & 水 IC & 214 & 小红皮 Xiaohongpi & - & 地方种 Landrace \\
\hline 95 & 长 4640 Chang 4640 & 2005 & 旱 DC & 215 & 牛趾甲(离石) Niuzhijia (Lishi) & - & 地方种 Landrace \\
\hline 96 & 汾黑麦 1831 Fenheimai 1831 & 2005 & 旱 DC & 216 & 红粒麦 Honglimai & - & 地方种 Landrace \\
\hline 97 & 晋麦 78 Jinmai 78 & 2006 & 旱 DC & 217 & 㖓州红 Jiangzhouhong & - & 地方种 Landrace \\
\hline 98 & 晋麦 79 Jinmai 79 & 2006 & 旱 DC & 218 & 假红麦 Jiahongmai & - & 地方种 Landrace \\
\hline 99 & 晋麦 80 Jinmai 80 & 2006 & 旱 DC & 219 & 牛趾甲(中阳) Niuzhijia (Zhongyang) & - & 地方种 Landrace \\
\hline 100 & 晋麦 81 Jinmai 81 & 2006 & 旱 DC & 220 & 四月黄 Siyuehuang & - & 地方种 Landrace \\
\hline 101 & 汾 4846 Fen 4846 & 2006 & 水 IC & 221 & 三月黄 Sanyuehuang & - & 地方种 Landrace \\
\hline 102 & 汾 4439 Fen 4439 & 2006 & 水 IC & 222 & 白芒䊁 Baimangcao & - & 地方种 Landrace \\
\hline 103 & 临旱 6 号 Linhan 6 & 2006 & 旱 DC & 223 & 有芒大红茎 Youmangdahongjing & - & 地方种 Landrace \\
\hline 104 & 运麦 218 Yunmai 218 & 2006 & 水 IC & 224 & 竹秆青 Zhuganqing & - & 地方种 Landrace \\
\hline 105 & 晋麦 82 Jinmai 82 & 2007 & 水 IC & 225 & 红秃麦(屯留) Hongtumai (Tunliu) & - & 地方种 Landrace \\
\hline 106 & 临汾 8050 Linfen 8050 & 2007 & 水 IC & 226 & 白秃麦(屯留) Baitumai (Tunliu) & - & 地方种 Landrace \\
\hline 107 & 晋麦 83 Jinmai 83 & 2007 & 水 IC & 227 & 白秃麦(吉县) Baitumai (Jixian) & - & 地方种 Landrace \\
\hline 108 & 临汾 6510 Linfen 6510 & 2007 & 水 IC & 228 & 红秃麦(吉县) Hongtumai (Jixian) & - & 地方种 Landrace \\
\hline 109 & 运旱 20410 Yunmai 20410 & 2007 & 旱 DC & 229 & 红蚰麦 Hongyoumai & - & 地方种 Landrace \\
\hline 110 & 长麦 6686 Changmai 6686 & 2007 & 水 IC & 230 & 红皮冬麦 Hongpidongmai & - & 地方种 Landrace \\
\hline 111 & 长 7016 Chang 7016 & 2007 & 旱 DC & 231 & 白山疙㾑 Baishangeda & - & 地方种 Landrace \\
\hline 112 & 中麦 175 Zhongmai 175 & 2007 & 水 IC & 232 & 红叶蚰 Hongyeyou & - & 地方种 Landrace \\
\hline 113 & 晋麦 84 Jinmai 84 & 2008 & 水 IC & 233 & 玉兰麦 Yulanmai & - & 地方种 Landrace \\
\hline 114 & 晋麦 85 Jinmai 85 & 2008 & 旱 DC & 234 & 紫麦 Zimai & - & 地方种 Landrace \\
\hline 115 & 晋太 9923 Jintai 9923 & 2008 & 水 IC & 235 & 大同小麦 Datongxiaomai & - & 地方种 Landrace \\
\hline 116 & 晋麦 86 Jinmai 86 & 2008 & 水 IC & 236 & 齐穗麦 Qisuimai & - & 地方种 Landrace \\
\hline 117 & 太 5902 Tai 5902 & 2008 & 水 IC & 237 & 大红麦 Dahongmai & - & 地方种 Landrace \\
\hline 118 & 长麦 6135 Changmai 6135 & 2008 & 旱 DC & 238 & 火烧头 Huoshaotou & - & 地方种 Landrace \\
\hline 119 & 晋麦 87 Jinmai 87 & 2009 & 旱 DC & 239 & 定兴寨小麦 Dingxingzhaixiaomai & - & 地方种 Landrace \\
\hline 120 & 运旱 719 Yunhan 719 & 2009 & 旱 DC & & & & \\
\hline
\end{tabular}

IC: irrigated cultivar; DC: dryland cultivar. 